\title{
Coexistence of follicular lymphoma and an unclassifiable myeloproliferative neoplasm in a treatment-naïve patient: A case report
}

\author{
GYEONGMIN JEONG ${ }^{1}$, JINHYONG KIM ${ }^{1}$, SEEUN HAN ${ }^{1}$, JONGMIN LEE ${ }^{1}$, KYUNGHYE PARK ${ }^{1}$, \\ CHUIYONG PAK ${ }^{1}$, JI-HUN LIM ${ }^{2}$, HEE JEONG CHA ${ }^{3}$, HAWK KIM $^{4}$ and JAE-CHEOL JO ${ }^{4}$ \\ Departments of ${ }^{1}$ Internal Medicine, ${ }^{2}$ Laboratory Medicine, ${ }^{3}$ Pathology and ${ }^{4}$ Hematology and Oncology, \\ Ulsan University Hospital, College of Medicine, University of Ulsan, Ulsan 682-714, Republic of Korea
}

Received October 21, 2014; Accepted June 16, 2015

DOI: $10.3892 / \mathrm{ol} .2015 .4040$

\begin{abstract}
Myeloproliferative neoplasms are associated with lymphoproliferative diseases following the administration of cytotoxic drugs or exposure to radiation, but are rare prior to therapy. The present study reports the case of a 61-year-old female with a history of transient ischemic attack. The patient, who presented with a palpable mass in the epitrochlear area of the left arm, was simultaneously diagnosed with follicular lymphoma and an unclassifiable myeloproliferative neoplasm. Excisional lymph node biopsy revealed stage I follicular lymphoma (grade 1). Laboratory findings demonstrated leukocytosis, erythrocytosis, thrombocytosis and decreased erythropoietin. Biopsy of the bone marrow revealed hypercellularity, with predominance of erythroid cells, and large polylobated megakaryocytes with increased mitotic figures, but no evidence of lymphomatous infiltration. The janus kinase 2 V617F mutation was also detected in the cells derived from the bone marrow specimen. Following local excision of the lymph node in the left epitrochlear area, radiation was delivered to the involved field, at a dose of $24 \mathrm{~Gy}$ in 12 fractions. The patient was started on hydroxyurea ( $1 \mathrm{~g}$ twice per day, orally) 2 weeks subsequent to radiotherapy, and was administered $500 \mathrm{mg}$ twice per day as maintenance therapy. At the six-month follow-up, the white blood cell count, hemoglobin levels and platelet count had reduced, and the patient was in a healthy condition. A computed tomography scan of the neck, chest and abdomen indicated no abnormalities. To the best of our knowledge, the present study is the first case
\end{abstract}

Correspondence to: Professor Jae-Cheol Jo, Department of Hematology and Oncology, Ulsan University Hospital, College of Medicine, University of Ulsan, 877 Bangeojinsunhwan-doro, Dong-gu, Ulsan 682-714, Republic of Korea

E-mail: jcjo97@hanmail.net

Key words: follicular lymphoma, unclassifiable myeloproliferative neoplasm, coexistence report of follicular lymphoma coexisting with an unclassifiable myeloproliferative neoplasm in a previously healthy patient. Molecular and genetic studies are required to further evaluate this infrequent disease association.

\section{Introduction}

Follicular lymphoma is an indolent B cell lymphoproliferative disorder of transformed follicular center B cells (1). Patients with follicular lymphoma present with diffuse lymphadenopathy, bone marrow involvement and splenomegaly; in rare cases, other extranodal sites may also be involved (1). Follicular lymphoma is one of the most common subtypes of non-Hodgkin lymphoma (NHL) with an estimated incidence of 3.18 cases per 100,000 individuals in the USA (2). Follicular lymphoma is the initial neoplasm for indolent lymphomas and has a median overall survival of $>10$ years (1). Observation or radiation therapy is adequate for asymptomatic and low tumor bulk disease cases $(3,4)$. For patients needing therapy, the majority of patients are treated with chemotherapy plus rituximab (5-7).

Myeloproliferative neoplasms are characterized by terminal myeloid cell expansion in the peripheral blood, resulting in various combinations of erythrocytosis, leukocytosis, thrombocytosis, bone marrow hypercellularity/fibrosis and splenomegaly (8). Polycythemia vera is a Philadelphia-negative myeloproliferative disease associated with JAK2 mutation characterized by erythrocytosis; patients are treated by phlebotomy and/or cytotoxic drugs (9). Myeloproliferative neoplasms are associated with lymphoproliferative disease following the administration of cytotoxic drugs or exposure to radiation, but are rarely observed prior to therapy $(10,11)$.

In the present study, a case of a 61-year-old female with a history of transient ischemic attack is reported. The patient was simultaneously diagnosed with follicular lymphoma and an unclassifiable myeloproliferative neoplasm. It is possible that the coexistence of follicular lymphoma and an unclassifiable myeloproliferative neoplasm prior to the administration of a cytotoxic drug or exposure to radiation may involve 2 unrelated clones of different lineages. 

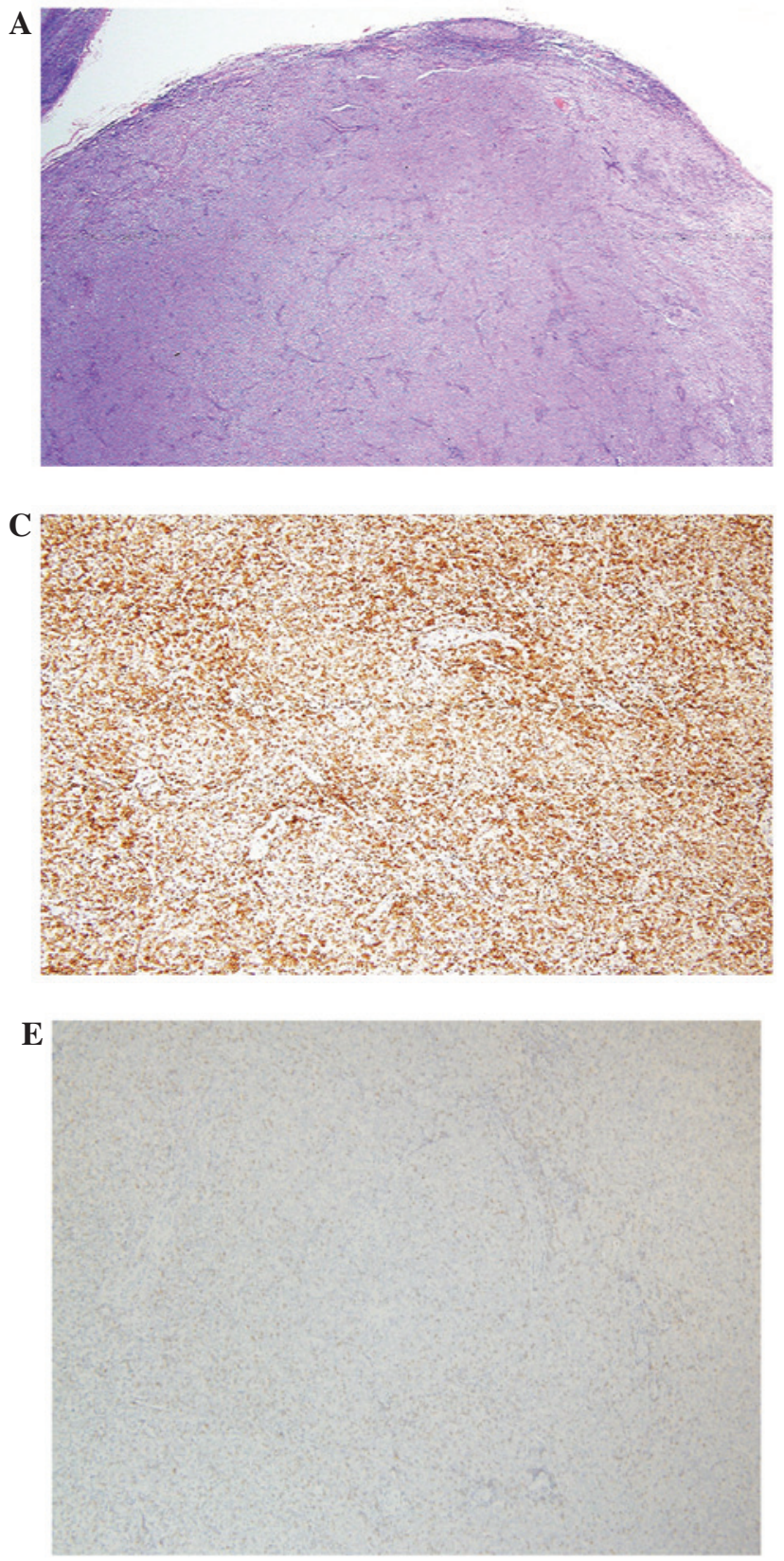
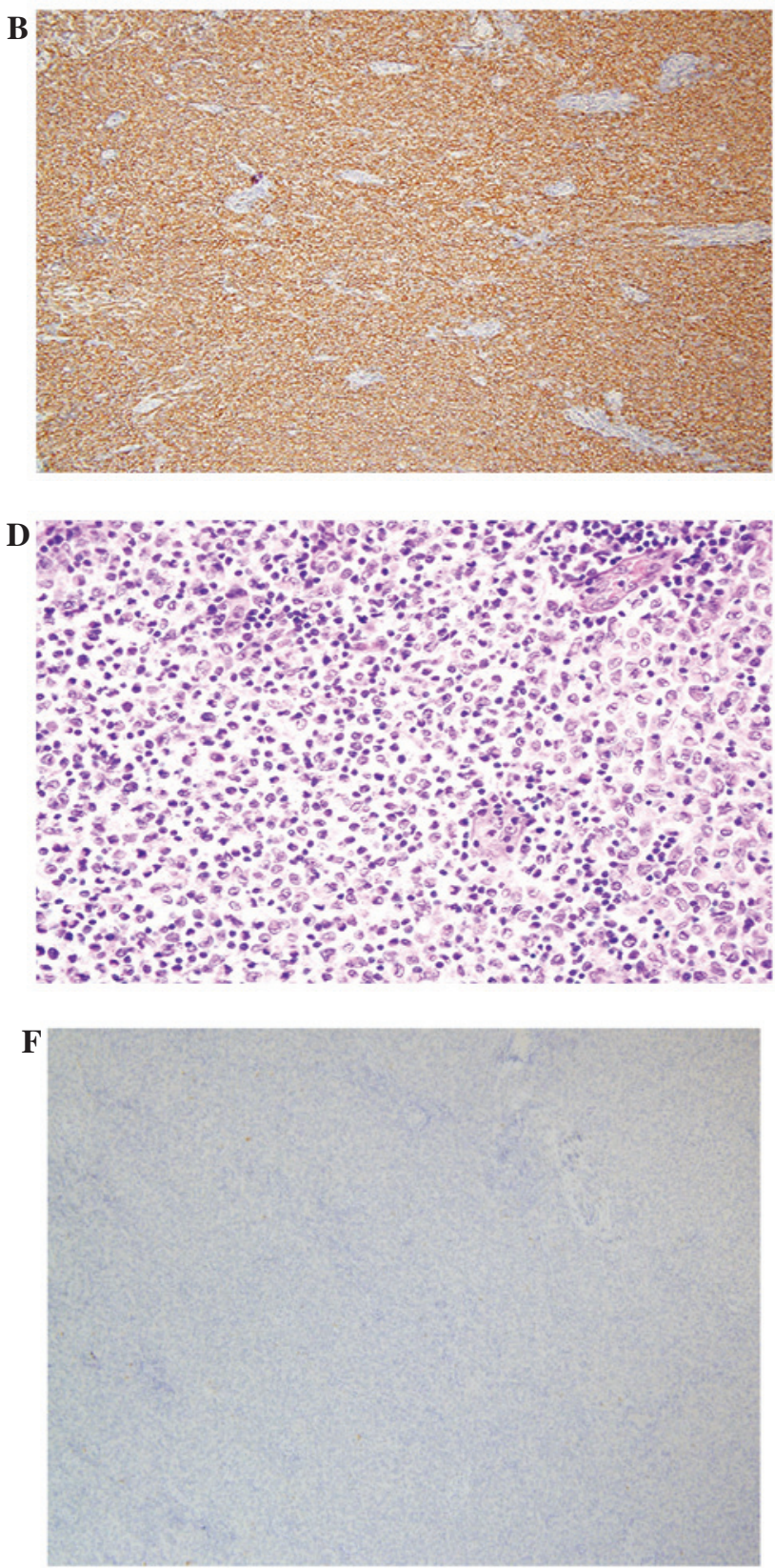

Figure 1. Histology of the epitrochlear lymph node demonstrated follicular lymphoma. (A) Hematoxylin and eosin staining; magnification, x20. (B) Positive immunohistochemical staining for cluster of differentiation 20 (brown); magnification, x100. (C) Positive immunohistochemical staining for B-cell lymphoma 2 (brown); magnification, x100. (D) Hematoxylin and eosin staining indicated nodal effacement by closely packed follicles, which contained small round cleaved cells and a number of larger cells with multiple nucleoli; magnification, $\mathrm{x} 400$. (E) Negative immunohistochemical staining for CD3 with scattered CD3-positive reactive T cells; magnification, x100. (F) Negative immunohistochemical stating for cyclin D1; magnification, x100.

\section{Case report}

A 61-year-old Asian female visited the Ulsan University Hospital (Dong-gu, Ulsan, Republic of Korea) in October 2013 with a painless but palpable left epitrochlear mass. The patient had suffered a transient ischemic attack in August 2010, and was prescribed aspirin (100 mg once per day) and cilostazol (100 mg once per day) at the time. The $1.5-\mathrm{cm}$ sized left epitrochlear mass presented without systemic B symptoms, such as fever, night sweat or unintentional weight loss. Laboratory findings demonstrated leukocytosis [white blood cell (WBC) count, 16,040 cells $/ \mu 1$ ], erythrocytosis (hemoglobin, $17.5 \mathrm{~g} / \mathrm{dl}$; hematocrit, 58.3\%), thrombocytosis (platelet count,
$782,000$ cells $/ \mu 1)$, reduced erythropoietin $(6.26 \mathrm{mU} / \mathrm{ml})$, elevated lactate dehydrogenase (789 IU/1) and elevated serum $\beta-2$ microglobulin $(2.8 \mathrm{mg} / \mathrm{l})$. A computed tomography scan of the neck, chest and abdomen identified an enlarged spleen, but no other lymphadenopathy. An excisional lymph node biopsy demonstrated follicular lymphoma with nodal growth pattern, which are closely packed and contained small round cleaved cells and larger non-cleaved cells (grade 1) (Fig. 1). The tumor cells were positive for B-cell lymphoma 2 (Bcl-2), cluster of differentiation (CD) 20, and negative for CD3 and cyclinD1. Positron emission tomography identified a mild hypermetabolic lesion in the operation bed of the left elbow, demonstrating post-surgery alteration. Diffusely increased 
Table I. Review of the association between PV and malignant lymphoma, prior to the administration of a cytotoxic agent and/or exposure to radiation.

\begin{tabular}{|c|c|c|c|c|c|}
\hline $\begin{array}{l}\text { Age } \\
\text { (years)/ } \\
\text { gender }\end{array}$ & $\begin{array}{l}\text { Histological } \\
\text { type of } \\
\text { lymphoma }\end{array}$ & $\begin{array}{l}\text { Timing of } \\
\text { diagnoses }\end{array}$ & Treatment & Outcomes & Reference \\
\hline $73 / \mathrm{M}$ & $\begin{array}{l}\text { Plasmacytoid } \\
\text { of the colon }\end{array}$ & Simultaneous & Melphalan & Not available & (15) \\
\hline $20 / M$ & $\begin{array}{l}\text { Immature } \\
\text { T-cell }\end{array}$ & Simultaneous & $\begin{array}{l}\mathrm{CTX}+\mathrm{ADM}+\mathrm{VCR}+\mathrm{VM} 26+\mathrm{PDN} \\
\text { plus CNS prophylaxis with MTX } \\
\text { +DEX; PDN+VCR+DNM } \\
\text { +asparaginase; m-BACOD }\end{array}$ & $\begin{array}{l}\text { No response and progression } \\
\text { of NHL, followed by } \\
\text { close mortality }\end{array}$ & (16) \\
\hline 78/M & $\begin{array}{l}\text { Cutaneous } \\
\text { T-cell }\end{array}$ & $\begin{array}{l}\text { Sequential (PV } \\
\text { detected } 1 \text { year } \\
\text { prior to NHL) }\end{array}$ & Phlebotomy; photochemotherapy & $\begin{array}{l}\text { Resolution of skin lesion; } \\
\text { stabilization of Hct; } \\
\text { leukocytosis; thrombocytosis }\end{array}$ & (17) \\
\hline $52 / \mathrm{M}$ & Hodgkin's & $\begin{array}{l}\text { Sequential (PV } \\
\text { detected } 9 \text { months } \\
\text { prior to NHL) }\end{array}$ & Phlebotomy; VLB; CVPP & $\begin{array}{l}\text { HL CR and reduction of PV; } \\
\text { recurrence of PV after } 4 \text { years } \\
\text { of chemotherapy withdrawal }\end{array}$ & (18) \\
\hline $66 / M$ & $\begin{array}{l}\text { Follicle center } \\
\text { cell (grade 1) }\end{array}$ & Simultaneous & m-BACOD; MIT+PDM; HU & $\begin{array}{l}\text { NHL CR; transformation } \\
\text { of PV into secondary MMM }\end{array}$ & (14) \\
\hline $61 / \mathrm{F}$ & $\begin{array}{l}\text { Follicular } \\
\text { (grade 1) }\end{array}$ & Simultaneous & $\begin{array}{l}\text { Local excision; radiation; } \\
\text { phlebotomy; aspirin; HU }\end{array}$ & $\begin{array}{l}\text { FL CR; stabilization of Hct; } \\
\text { leukocytosis; thrombocytosis }\end{array}$ & $\begin{array}{l}\text { Present } \\
\text { report }\end{array}$ \\
\hline
\end{tabular}

PV, polycythemia vera; M, male; F, female; NHL, non-Hodgkin's lymphoma; CTX, cyclophosphamide; ADM, adriamycin; VCR, vincristine; VM26, teniposide; PDN, prednisone; CNS, central nervous system; MTX, methotrexate; DEX, dexamethasone; DNM, daunomycin; m-BACOD, MTX+bleomycin+ADM+CTX+VCR+DEX; VLB, vinblastine; CVPP, CTX+VCR+PDN+procarbazine; MIT, mitoxantrone; PDM, prednimustine; HU, hydroxyurea; Hct, hematocrit; HL, Hodgkin's lymphoma; CR, complete remission; MMM, myeloid metaplasia with myelofibrosis; FL, follicular lymphoma.
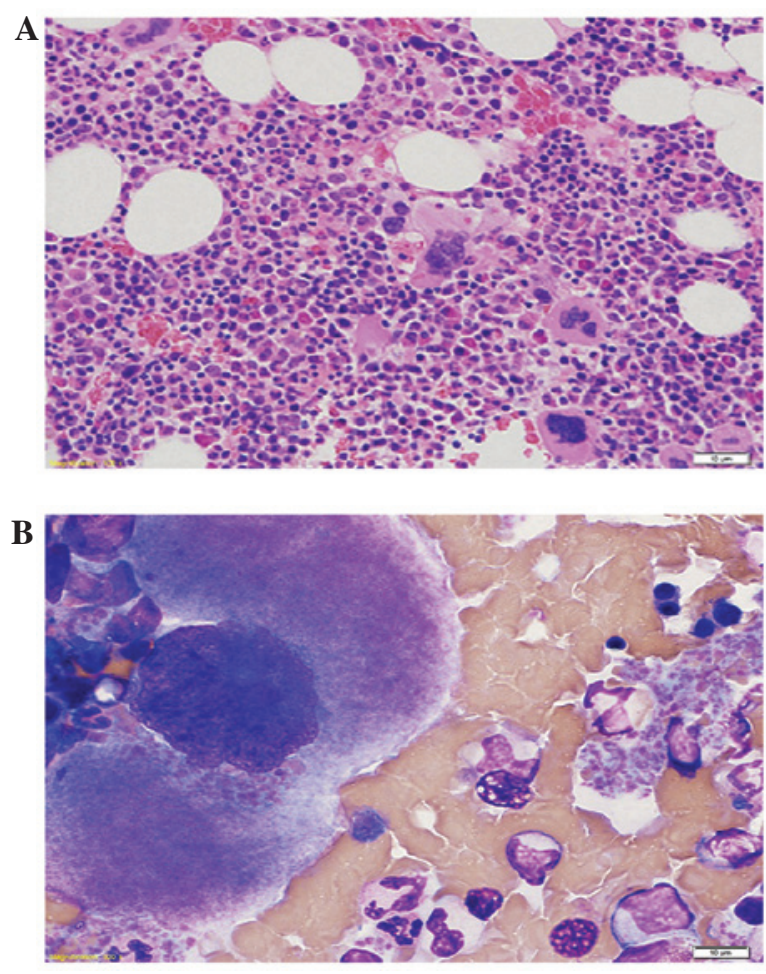

Figure 2. No evidence of lymphomatous infiltrations was observed on bone marrow aspiration and biopsy. (A) Biopsy of the bone marrow revealed hypercellularity with predominance of erythroid cells; Hematoxylin and eosin staining, magnification, x200. (B) Aspirates of the bone marrow showed large polylobated megakaryocytes and platelet clumping; Wright staining, magnification, x1000. metabolism of the skeletal bone marrow was also observed throughout the body. A biopsy of the bone marrow revealed hypercellularity, with predominance of cells derived from the erythroid series and large polylobated megakaryocytes with increased mitotic figures. However, no evidence of lymphomatous infiltration was observed (Fig. 2). The V617F mutation in janus kinase 2 (JAK2) was also detected in the cells of the bone marrow specimen. Based on these results, the disease was considered to be at a clinical stage I, and the follicular lymphoma international prognostic index score indicated an intermediate risk (12). Following local excision of the lymph node, radiation was delivered to the involved field at a dose of 24 Gy in 12 fractions. A computed tomography scan of the neck, chest and abdomen performed 3 months later revealed no abnormalities. Following phlebotomy and plasma apheresis, the patient was started on hydroxyurea $(1 \mathrm{~g}$ twice per day, orally) 2 weeks subsequent to the end of radiotherapy, and was administered $500 \mathrm{mg}$ twice per day of the drug as maintenance therapy. On the sixth month of follow-up, the WBC count, hemoglobin, hematocrit and platelet count were reduced to 7,430 cells $/ \mu \mathrm{l}, 12.2 \mathrm{~g} / \mathrm{dl}, 36.5 \%$ and 379,000 cells $/ \mu 1$, respectively, and the patient was in a healthy condition at the time of reporting.

\section{Discussion}

A small number of patients $(<10 \%)$ diagnosed with follicular lymphoma present stage I/II of the disease (13). In these 
cases, radiation therapy is the treatment of choice, following which, the 10 -year overall survival rate is $60-80 \%$, with a median survival time of $\sim 19$ years (3). The therapies for polycythemia vera are aimed at preventing the occurrence of thrombosis $(19,20)$. The initial therapy for patients at high risk of developing thrombosis consists of phlebotomy plus a low dose of aspirin, supplemented with a cytoreductive agent, such as hydroxyurea (21). In the present report, radiation was delivered to the involved field, following local excision of the lymph node in the left epitrochlear area. The patient was administered hydroxyurea and aspirin subsequent to phlebotomy and plasma apheresis.

Direct or indirect dysregulation of the tyrosine kinase JAK2 signaling pathway, as a result of somatically acquired mutations, is involved in the pathogenesis of myeloproliferative neoplasms (22). JAK2 participates in the signaling pathways initiated by the cytokine receptors that are required for normal myelopoiesis, including those for erythropoietin, thrombopoietin and granulocyte colony stimulating factor (23). The JAK2 V617F variant increases genomic instability by reducing apoptosis secondary to DNA damage, and by altering the expression of a number of genes, which in turn may increase the risk of genetic lesions that lead to leukemic transformation (24).

The JAK2 V617F mutation is present in 95\% of patients with polycythemia vera and in $\sim 50 \%$ of patients with primary myelofibrosis or essential thrombocythemia $(24,25)$. This mutation has also been observed in patients affected by other myeloid diseases, including $67 \%$ of patients with refractory anemias and ring sideroblasts associated with thrombocytosis (26), $7.8 \%$ of patients with chronic myelomonocytic leukemias and a low percentage of patients with primary acute myeloblastic leukemias, myelodysplastic syndromes and chronic myeloid leukemia (27). However, to the best of our knowledge, the JAK2 V617F mutation has not been detected in follicular lymphoma thus far. Furthermore, the coexistence of follicular lymphoma and myeloproliferative neoplasm is rare $(14,28)$.

There are limited number of reports in the literature that are relevant to the case described in the present report (Table I). It is uncertain whether there is a pathogenetic association between the myeloproliferative and lymphoproliferative diseases: It is likely that both are as a result of random mutations occurring in distinct initiating cells. However, given the higher risk of lymphoproliferative neoplasms development in myeloproliferative neoplasms reported in larger studies, the genomic instability characteristic to myeloproliferative neoplasms may contribute to subsequent lymphoproliferative neoplasms occurrence $(29,30)$. The pathogenesis may be attributed to reduced immunocompetence and/or anti oncogene suppression.

In the present study, the JAK2 V617F mutation was identified in the malignant cells of a patient with an unclassifiable myeloproliferative neoplasm and coexisting follicular lymphoma. This finding may indicate that the JAK2 V617F mutation represents a secondary event to primary gene mutations in the primitive stem cells, which leads to the development of a follicular lymphoma and an unclassifiable myeloproliferative neoplasm. Regardless, further studies using molecular and genetic approaches may aid in the understanding of this rare occurrence of neoplasms.

\section{References}

1. Freedman A: Follicular lymphoma: 2014 update on diagnosis and management. Am J Hematol 89: 429-436, 2014.

2. Morton LM, Wang SS, Devesa SS, Hartge P, Weisenburger DD and Linet MS: Lymphoma incidence patterns by WHO subtype in the United States, 1992-2001. Blood 107: 265-276, 2006.

3. Guadagnolo BA, Li S, Neuberg D, Ng A, Hua L, Silver B, Stevenson MA and Mauch P: Long-term outcome and mortality trends in early-stage, Grade 1-2 follicular lymphoma treated with radiation therapy. Int J Radiat Oncol Biol Phys 64: 928-934, 2006.

4. Advani R, Rosenberg SA and Horning SJ: Stage I and II follicular non-Hodgkin's lymphoma: long-term follow-up of no initial therapy. J Clin Oncol 22: 1454-1459, 2004.

5. Hiddemann W, Kneba M, Dreyling M, Schmitz N, Lengfelder E, Schmits R, Reiser M, Metzner B, Harder H, Hegewisch-Becker S, et al: Frontline therapy with rituximab added to the combination of cyclophosphamide, doxorubicin, vincristine, and prednisone (CHOP) significantly improves the outcome for patients with advanced-stage follicular lymphoma compared with therapy with CHOP alone: Results of a prospective randomized study of the German Low-Grade Lymphoma Study Group. Blood 106: 3725-3732, 2005.

6. Marcus R, Imrie K, Belch A, Cunningham D, Flores E, Catalano J, Solal-Celigny P, Offner F, Walewski J, Raposo J, et al: CVP chemotherapy plus rituximab compared with CVP as first-line treatment for advanced follicular lymphoma. Blood 105: 1417-1423, 2005

7. Marcus R, Imrie K, Solal-Celigny P, Catalano JV, Dmoszynska A, Raposo JC, Offner FC, Gomez-Codina J, Belch A, Cunningham D, et al: Phase III study of R-CVP compared with cyclophosphamide, vincristine, and prednisone alone in patients with previously untreated advanced follicular lymphoma. J Clin Oncol 26: 4579-4586, 2008.

8. Dickstein JI and Vardiman JW: Hematopathologic findings in the myeloproliferative disorders. Semin Oncol 22: 355-373, 1995.

9. Tefferi A and Barbui T: Polycythemia vera and essential thrombocythemia: 2015 update on diagnosis, risk-stratification and management. Am J Hematol 90: 162-173, 2015.

10. Montefusco E, Fazi F, Cordone I, Ariola C, Nanni M, Spadea A, Spiriti MA, Fenu S, Mandelli F, Petti MC, et al: Molecular remission following high-dose hydroxyurea and fludarabine plus cytarabine in a patient with simultaneous acute myeloid leukemia and low-grade lymphoma. Leuk Lymph 40: 671-674, 2001.

11. Ornellas De Souza MH, de Souza Fernandez T, Diamond HR, Maioli MC, Pitanga Bacha PC and De Lucena SB: Cytogenetic and immunophenotypic evidence of independent clonal origins of concomitant chronic lymphocytic leukaemia and acute myeloid leukaemia. Eur J Haematol 66: 281-283, 2001.

12. Solal-Céligny P, Roy P, Colombat P, White J, Armitage JO, Arranz-Saez R, Au WY, Bellei M, Brice P, Caballero D, et al: Follicular lymphoma international prognostic index. Blood 104: 1258-1265, 2004.

13. Friedberg JW, Byrtek M, Link BK, Flowers C, Taylor M, Hainsworth J, Cerhan JR, Zelenetz AD, Hirata J and Miller TP: Effectiveness of first-line management strategies for stage I follicular lymphoma: Analysis of the National LymphoCare Study. J Clin Oncol 30: 3368-3375, 2012.

14. Rizzi R, Liso A, Pannunzio A, Carluccio P, Specchia G and Liso V: Concomitant primary polycythemia vera and follicle center cell non-Hodgkin lymphoma: A case report and review of the literature. Leuk Lymph 43: 2217-2220, 2002.

15. Guzzini F, Cozzi C, Gasparini P, Giussani R and Tomasi A: Spontaneous association of a chronic lympho- and myeloproliferative disease in the same patient. Description of 2 cases. Recenti Prog Med 79: 365-369, 1988.

16. Kurchan A, Somoza N, Pascuccelli H, Mide S, Padros MR, Santiago J, Satz ML and Fainboim L: T lymphoma of immature phenotype associated with polycythemia vera. Medicina (B Aires) 51: 151-154, 1991.

17. Cottrill C, Geller A, diSpaltro FX, Weissglass B, Klainer AS and Bisaccia E: Control of polycythaemia vera with photochemotherapy in a patient with cutaneous T-cell lymphoma. Br J Haematol 86: 225-226, 1994.

18. Stolinsky DC: Twelve-year remission of polycythemia vera following Hodgkin's disease and chemotherapy. CA Cancer J Clin 31: 57-60, 1981.

19. Chievitz E and Thiede T: Complications and causes of death in polycythaemia vera. Acta Medica Scand 172: 513-523, 1962. 
20. Patrono C, Rocca B and De Stefano V: Platelet activation and inhibition in polycythemia vera and essential thrombocythemia. Blood 121: 1701-1711, 2013.

21. Hensley B, Geyer H and Mesa R: Polycythemia vera: Current pharmacotherapy and future directions. Expert Opin Pharmacother 14: 609-617, 2013.

22. Oh ST and Gotlib J: JAK2 V617F and beyond: Role of genetics and aberrant signaling in the pathogenesis of myeloproliferative neoplasms. Expert Rev Hematol 3: 323-337, 2010.

23. Muxi PJ and Oliver AC: Jak-2 positive myeloproliferative neoplasms. Curr Treat Options Oncol 15: 147-156, 2014

24. Cross NC: Genetic and epigenetic complexity in myeloproliferative neoplasms. Hematology Am Soc Hematol Educ Program 2011: 208-214, 2011.

25. Jones AV, Kreil S, Zoi K, Waghorn K, Curtis C, Zhang L, Score J, Seear R, Chase AJ, Grand FH, et al: Widespread occurrence of the JAK2 V617F mutation in chronic myeloproliferative disorders. Blood 106: 2162-2168, 2005.

26. Ceesay MM, Lea NC, Ingram W, Westwood NB, Gäken J, Mohamedali A, Cervera J, Germing U, Gattermann N, Giagounidis A, et al: The JAK2 V617F mutation is rare in RARS but common in RARS-T. Leukemia 20: 2060-2061, 2006.
27. Levine RL1, Loriaux M, Huntly BJ, Loh ML, Beran M, Stoffregen E, Berger R, Clark JJ, Willis SG, Nguyen KT, et al: The JAK2V617F activating mutation occurs in chronic myelomonocytic leukemia and acute myeloid leukemia, but not in acute lymphoblastic leukemia or chronic lymphocytic leukemia. Blood 106: 3377-3379, 2005.

28. Kuroda H1, Abe T, Jomen W, Yoshida $\approx$ M, Matsuno T, Sato M, Yamada M, Sakurai T, Fujii S, Maeda M, et al: [Follicular lymphoma complicated with myelofibrosis and macroglobulinemia at initial presentation]. Rinsho ketsueki 54: 2068-2073, 2013 (In Japanese)

29. Vannucchi AM, Masala G, Antonioli E, Susini MC, Guglielmelli P, Pieri L, Maggi L, Caini S, Palli D, Bogani C, et al: Increased risk of lymphoid neoplasms in patients with Philadelphia chromosome-negative myeloproliferative neoplasms. Cancer Epidemiol Biomarkers Prev 18: 2068-2073, 2009.

30. Rumi E, Passamonti F, Elena C, Pietra D, Arcaini L, Astori C, Zibellini S, Boveri E, Pascutto C and Lazzarino M: Increased risk of lymphoid neoplasm in patients with myeloproliferative neoplasm: A study of 1,915 patients. Haematologica 96: 454-458, 2011 (In Italian). 